\title{
Anticipation of visual form independent of knowing where the form will occur
}

\author{
Pernille Bruhn • Claus Bundesen
}

Published online: 14 April 2012

(C) Psychonomic Society, Inc. 2012

\begin{abstract}
We investigated how selective preparation for specific forms is affected by concurrent preknowledge of location when upcoming visual stimuli are anticipated. In three experiments, participants performed a two-choice response time (RT) task in which they discriminated between standard upright and rotated alphanumeric characters while fixating a central fixation cross. In different conditions, we gave the participants preknowledge of only form, only location, both location and form, or neither location nor form. We found main effects of both preknowledge of form and preknowledge of location, with significantly lower RTs when preknowledge was present than when it was absent. Our main finding was that the two factors had additive effects on RTs. A strong interaction between the two factors, such that preknowledge of form had little or no effect without preknowledge of location, would have supported the hypothesis that form anticipation relies on depictive, perception-like activations in topographically organized parts of the visual cortex. The results provided no support for this hypothesis. On the other hand, by an additivefactors logic Sternberg (Sternberg, Acta Psychologica 30:276$315,1969)$, the additivity of our effects suggested that preknowledge of form and location, respectively, affected two functionally independent, serial stages of processing. We suggest that the two stages were, first, direction of attention to the stimulus location and, subsequently, discrimination between upright and rotated stimuli. Presumably, preknowledge of location advanced the point in time at which attention was directed
\end{abstract}

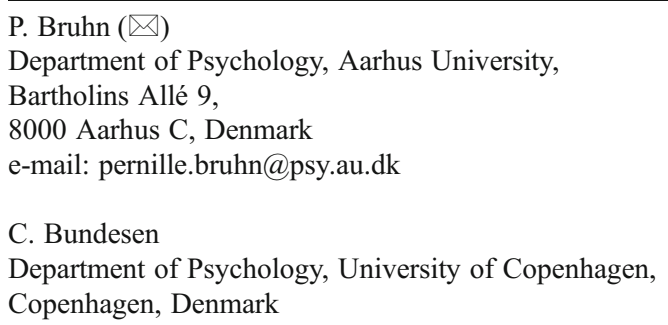

at the stimulus location, whereas preknowledge of form reduced the time subsequently taken for stimulus discrimination.

Keywords Foreknowledge $\cdot$ Preknowledge $\cdot$ Form cuing . Location cuing - Visual attention

Anticipation of future events on the basis of preknowledge about these events is a ubiquitous and highly adaptive function in our interactions with the world (e.g., Anokhin, 1974; Feigenberg, 1969; Llinás, 2001; Pezzulo, Hoffmann, \& Falcone, 2007; Sokolov, Spinks, Näätänen, \& Lyytinen, 2002; Summerfield \& Egner, 2009). Investigations of anticipatory processes in visual perception and attention have concerned three classes of preknowledge that are potentially relevant when predicting upcoming visual stimuli: temporal preknowledge (concerning the time of onset of the event), spatial preknowledge (concerning the location within the visual field of the event), and featural preknowledge (concerning the content of the event, such as the form of an object).

The presence of temporal (Niemi \& Näätänen, 1981; Nobre, Correa, \& Coull, 2007) and, especially, spatial preknowledge (Downing, 1988, and Posner, 1980, among many others) has repeatedly proved useful to perceivers in experimental tasks, as measured by reductions in response times (RTs) or increases in accuracy. Moreover, many researchers have found that RTs are faster to a specific letter that has a high probability of occurring (in a given task or a given trial) than to a less probable letter (Kingstone, 1992; Kingstone \& Klein, 1991; Mattes, Ulrich, \& Miller, 2002; Miller \& Anbar, 1981) and that this effect generalizes to letters that have a similar visual shape (Dykes \& Pascal, 1981). Thus, it seems that we can also use form-related preknowledge to prepare selectively for a specific visual form. However, this type of anticipation has generally been less wellinvestigated than anticipation based on spatial and temporal preknowledge, and not much is known about the processes 
underlying form anticipation or about how form preknowledge relates to and interacts with the other types of preknowledge. The purpose of the present study was to acquire more knowledge about the nature of visual form anticipation by examining its interaction with anticipation based on preknowledge of location. Specifically, we wanted to investigate whether anticipation of visual form is dependent on knowing where the form will occur - that is, whether form anticipation is spatially bound. This is an important question because determining whether visual form anticipation relies on location-bound or location-invariant representation has great implications for our understanding of how selective preparation for specific forms can be brought about by our visual system.

\section{Cuing paradigm}

When investigating the effect of preknowledge on perception, the focus in the literature has usually been on the difference between validly cued (expected) and invalidly cued (surprising) events. Most investigations have used the cost-benefit paradigm of Posner (1980), in which participants are given probabilistic cues that are sometimes valid, sometimes invalid, and sometimes neutral (see Jonides \& Mack, 1984, for an instructive review). An apparent weakness of this paradigm is the fact that surprising stimuli (i.e., those that mismatch expectations generated by invalid cuing) are likely to raise the level of arousal (see, e.g., Berlyne, 1963), which may affect the speed of both perceptual and motoric processing (see Vangkilde, Coull, \& Bundesen, 2012). In the present study, we wanted to measure, as precisely as possible, the temporal effects of having (100\% valid) versus not having preknowledge of form and location. Therefore, rather than contrasting expected and surprising events, we gave participants either $100 \%$ valid cues (preknowledge-present condition) or uninformative (neutral) cues (preknowledge-absent condition). ${ }^{1}$

\footnotetext{
${ }^{1}$ Referring to Jonides and Mack (1984), an anonymous reviewer argued that "comparing $100 \%$ valid cues with neutral cues is not without drawbacks. . . . Perhaps the key concern here is that the mental state of the participant before the target is different following a valid cue than following a neutral cue. One might reasonably infer that an informative cue will elicit some consistent mental state, while a noninformative (neutral) precue may not. In the case of the neutral form cue, it may elicit all potential stimuli, the stimulus from the previous trial, a 'guess,' or perhaps none at all. We don't know. In the case of a noninformative spatial cue, there may [be] no accompanying shift of attention to a location as there would be following the informative cue. Moreover, for both location and form, the neutral cue may elicit a lower degree of response readiness because there is less certainty about what will be shown where." Thus, in principle, our approach of contrasting more with less specific cuing (100\%-valid vs. neutral cues), instead of contrasting the effects of generally valid cues with the effects of misleading (invalid) cues, may also lead to serious confounds.
}

\section{Previous cuing studies}

Our preknowledge-absent condition corresponded closely to the neutral condition in probabilistic cuing paradigms, and our preknowledge-present condition was a $100 \%$-valid cuing condition, so we were interested in findings from previous studies regarding the difference between a valid and a neutral condition. Two of the previous studies investigating the effects of combined preknowledge of form and location included a neutral condition (Kingstone, 1992, Exp. 1; Lambert \& Hockey, 1986, Exp. 1). In these two studies, participants made a speeded orientation judgment about one of two shapes (A vs. V and an ellipse vs. a diamond, respectively) that appeared either to the left or to the right of a central fixation cross. The location and/or the form of the upcoming stimulus were cued with either a neutral cue or a generally valid cue. In both studies, reduced RTs were found after valid relative to neutral location cuing. A similar effect on RTs of form preknowledge was present in Kingstone's study, but only to some degree in Lambert and Hockey's study. Only Kingstone tested how the presence of (valid) location preknowledge, as compared with no (i.e., neutral) location preknowledge, modulated the effect of form preknowledge. He found a seemingly additive effect between the two types of preknowledge when comparing the valid and neutral conditions. However, it should be stressed that although both Kingstone's and Lambert and Hockey's studies used a covert spatial attention task in which participants were required to fixate a central cross, none of the studies controlled for fixation. Hence, their results concerning the effects of location cuing and its interaction with form preknowledge are potentially unreliable.

Whereas Kingstone (1992, Exp. 1) found additive RT effects of location and form preknowledge when comparing the valid and neutral conditions, he found a significant interaction between the two factors when including the results from the invalid condition in the analysis. Specifically, he reported "an unusual delay" in RTs when expectancies mismatched, such that a surprising form appeared at an expected location or an expected form appeared at a surprising location. Kingstone noted that the interaction might result from crosstalk between the dimensions of location and form: If a location expectancy is confirmed, observers may increase their attentional commitment to the possibility that the form expectancy will also be confirmed; if a location expectancy is disconfirmed, they may decrease their attentional commitment to the possibility that the form expectancy will be confirmed. Alternatively, we note, the interaction between the effects of location and form preknowledge may have been caused by a (motivational) interaction between the arousing effect of surprise due to mismatch with location expectations and the arousing effect of surprise due to mismatch with form expectations. 


\section{Relation to mental imagery}

It has been proposed that mental imagery of a given sensory event is functionally and neurophysiologically similar to selectively preparing for the perception of that same event (Barsalou, 2009; Farah, 1989; Kosslyn \& Thompson, 2003; Neisser, 1976, 1978). For example, the perceptual anticipation theory of visual imagery formulated by Kosslyn \& Thompson (2003) states that "the mechanisms used to generate mental images rely on processes used to anticipate perceiving stimuli" (p. 725). Indeed, both visual and auditory imagery of a specific stimulus have been found to enhance subsequent processing of that stimulus, as does anticipation (Farah \& Smith, 1983; Peterson \& Graham, 1974). Interestingly, the perceptual enhancement following visual imagery of a distinct visual form is abolished if the form is imaged at a different location in the visual field from where it actually occurs (Farah, 1985). This finding indicates that a mental image of a distinct form has an "array format" and is bound to a distinct location in the visual field (Farah, 1985). Moreover, a comprehensive meta-analysis of studies using brain-imaging techniques during visual imagery found that the topographically organized part of the visual cortex known as V1 is consistently activated during imagery of precise visual forms (Kosslyn \& Thompson, 2003). This supports the view put forth in the perceptual anticipation theory of visual imagery (Kosslyn \& Thompson, 2003) that the neural substrate of imaging a distinct visual form is a depictive neural activation pattern in $\mathrm{V} 1$, which is similar to the activation pattern elicited in this area when actually perceiving that form. This is also in line with two more broadly formulated views: the very old idea that a mental image is like a "faint copy" of a prior percept (Hume, 1896) and the more recently formulated notion that modal (i.e., perception-like) neural "simulations" of real events are the basis of both anticipation and imagery (Barsalou, 2009). Convergent evidence from a patient with a partially removed primary visual cortex (Farah, Soso, \& Dasheiff, 1992) and from a study in which V1 activity was disrupted by transcranial magnetic stimulation during visual imagery (Kosslyn et al., 1999) moreover suggests that activation of V1 plays a necessary functional role in imagery of distinct visual forms.

In line with the idea that anticipation and imagery have a common neural basis, several findings have indicated that perception-like neural activations in primary sensory areas also are involved when we prepare ourselves to perceive a stimulus. First, anticipatory neural activations measured before the arrival of an expected stimulus involve activations in early sensory areas corresponding to the modality of the upcoming stimulus (Bastiaansen \& Brunia, 2001; Carlsson, Petrovic, Skare, Petersson, \& Ingvar, 2000; Voisin, BidetCaulet, Bertrand, \& Fonlupt, 2006). Moreover, in visual anticipation, knowledge of the spatial location of an upcoming stimulus has been associated with prestimulus activations in areas of V1 corresponding topographically to the region of the expected location (Sylvester, Shulman, Jack, \& Corbetta, 2007). It could thus be speculated that depictive perceptionlike activations in V1 also play a crucial role in the preparation to perceive a particular visual form. This would mean that visual form anticipation is unavoidably integrated with spatial anticipation. In other words, the preparation for a visual form would need to be the preparation for a form situated in (twodimensional) space. If this is the case, we might expect that one would need concurrent information about location in order to efficiently use form preknowledge to prepare for a specific visual form. Thus, if form preknowledge of an upcoming visual stimulus has an effect on the RT to the stimulus only when the location of the upcoming stimulus is known, this would support the view that visual form anticipation is intrinsically spatially bound, and possibly relies on perception-like activations in topographically organized areas of the brain.

The hypothesis that knowing the specific form of an upcoming visual stimulus affects processing of the stimulus only when its location is also known is not supported by Kingstone's (1992) study. Kingstone found an effect of form preknowledge both when the location was "known" (i.e., precued with a valid cue) and "unknown" (i.e., precued with a neutral cue). In fact, in Kingstone's study, the effect of form cuing was not even larger when the location was valid than when it was neutral. However, the anticipated visual form could only occur at two different locations in Kingstone's study. Introspectively, it seems possible to simultaneously imagine a not-too-complex form, say the letter A, at two predefined locations that are not too far apart. This becomes increasingly difficult when one tries to imagine the form at multiple predefined locations. Consider the possibility that when the location was precued with a neutral cue in Kingstone's study, the participants prepared for the upcoming form (when known) by simultaneously imaging the upcoming form at both possible locations. This strategy could have allowed the participants in Kingstone's study to benefit from preknowledge of form through the posited depictive activations in topographically organized areas of the visual cortex, even when the location was "unknown." Considering this potential methodological problem, together with the above-mentioned lack of fixation control, Kingstone's study does not seem sufficient for concluding about how anticipation of visual form may be influenced by the presence versus absence of location preknowledge.

\section{General method}

In order to investigate how the effect of form preknowledge may be influenced by the availability of simultaneous location preknowledge, it will be essential to establish the existence of 
a robust behavioral effect of knowing the form of a visual stimulus before it occurs. Therefore, we had participants do an orientation judgment task of alphanumeric characters that were presented either in their standard upright orientation or in one of several rotated orientations. In order to solve this task, the participants needed to identify the form of the character. The use of several rotated orientations (rather than just a single rotation) should force the participants to make a more thorough analysis of the form of the stimulus characters in order to do the task. We assumed that, under these circumstances, we would observe significant effects of form preknowledge. The presence of preknowledge was varied in a $2 \times 2$ design, in which information about (a) form, (b) location, (c) both form and location, or (d) neither form nor location was given in advance. Finally, we amended the methodological weaknesses of Lambert and Hockey's (1986) and Kingstone's (1992) studies by including fixation control and a larger set of possible locations.

\section{Trial procedure}

A diagram of a single trial is shown in Fig. 1. In the first display, a central fixation cross was present, and above it the following text was displayed: "Fixate on the fixation cross and press SPACEBAR to start the next trial." Above this text, digits indicated the number of the current trial. The participants initiated each trial by pressing the spacebar when ready. After $500 \mathrm{~ms}$, one of nine possible auditory form cues was played back. Then, 2,000 ms after the onset of the form cue, one of nine possible location cues was displayed centrally over the fixation cross for $500 \mathrm{~ms}$. The fixation cross next reappeared and, after an interval of 2,000 ms, one of eight possible alphanumeric characters (the target) appeared on the screen at one of the eight possible locations. The participants' task was to indicate whether the alphanumeric character was in its standard, upright form or was rotated by pressing one of two response buttons on a standard computer keyboard. The character stayed on the screen until the participants had responded.

\section{Stimuli}

On half of the trials, the auditory form cue was the utterance "all" (form preknowledge absent), and on the other half of the trials, it was a specific alphanumeric character read aloud (form preknowledge present). ${ }^{2}$ The specific character was drawn from a set composed of eight possible alphanumeric characters

\footnotetext{
${ }^{2}$ Pilot studies showed that the auditory cuing procedure seemed natural to the participants. Presenting the corresponding cues (the word "all" vs. a specific alphanumeric character) in the visual modality seemed less appropriate, as this might induce a special strategy of using the single-character cues as templates to be matched against the imperative stimuli.
}

(see Fig. 2). The location cue was an " $\times$ " symbol (location preknowledge absent $)$ on half of the trials and an arrow pointing at one of eight possible target locations (location preknowledge present) on the other half of the trials. The eight possible target locations were placed on a virtual circle with its center on the fixation cross and a radius of $4.5 \mathrm{deg}$ of visual angle. The target was drawn from a set of eight possible alphanumeric characters (see Fig. 2). On half of the trials, the target occurred in its standard upright position, and on the other half it appeared in one of three or four nonstandard orientations. All of the visual stimuli were black and presented on a white background. The location cues subtended approximately $0.8 \times 0.8 \mathrm{deg}$ of visual angle, and the targets subtended approximately $0.8 \times 0.6 \mathrm{deg}$ of visual angle. The durations of the different sound files of the nine auditory form cues ranged from 830 to $1,270 \mathrm{~ms}$ (average duration $=1,025 \mathrm{~ms}$ ) in Experiment 1 and were kept constant at $750 \mathrm{~ms}$ in Experiments 2 and 3.

\section{Apparatus}

The experiments were run on an IBM PC computer with a 19 -in. SVGA color monitor $(640 \times 480,100 \mathrm{~Hz})$. The stimuli were presented, responses were recorded, and the timing of events was controlled using E-Prime 2.0. Participants' gaze direction was recorded with an EyeLink 1000 Desktop Mount eyetracker $($ sampling rate $=1000 \mathrm{~Hz}$ ).

\section{Design}

The location-preknowledge-present cue and the form-preknowledge-present cue were both $100 \%$ valid, and the location-preknowledge-absent cue and the form-preknowledge-absent cue were both completely uninformative. Hence, after the arrow location cue, the target would always occur at the indicated location, and after the " $\times$," the target could occur on any of the eight locations with equal probability. After a specific alphanumeric character had been read aloud, this specific character would always occur as the target on the current trial, and after the utterance "all," any of the eight possible targets could occur with equal probability. All of the eight possible targets occurred with equal frequency, and each of them occurred equally frequently at each of the eight locations. Four combinations of preknowledge existed: (a) form preknowledge present and location preknowledge absent, (b) form preknowledge absent and location preknowledge present, (c) form preknowledge present and location preknowledge present, and (d) form preknowledge absent and location preknowledge absent. Each of these four preknowledge combinations occurred with equal frequency over the experiment. The cues, targets, and target locations occurred in a sequence that was randomized anew for each participant. 
Fig. 1 Example of a single trial

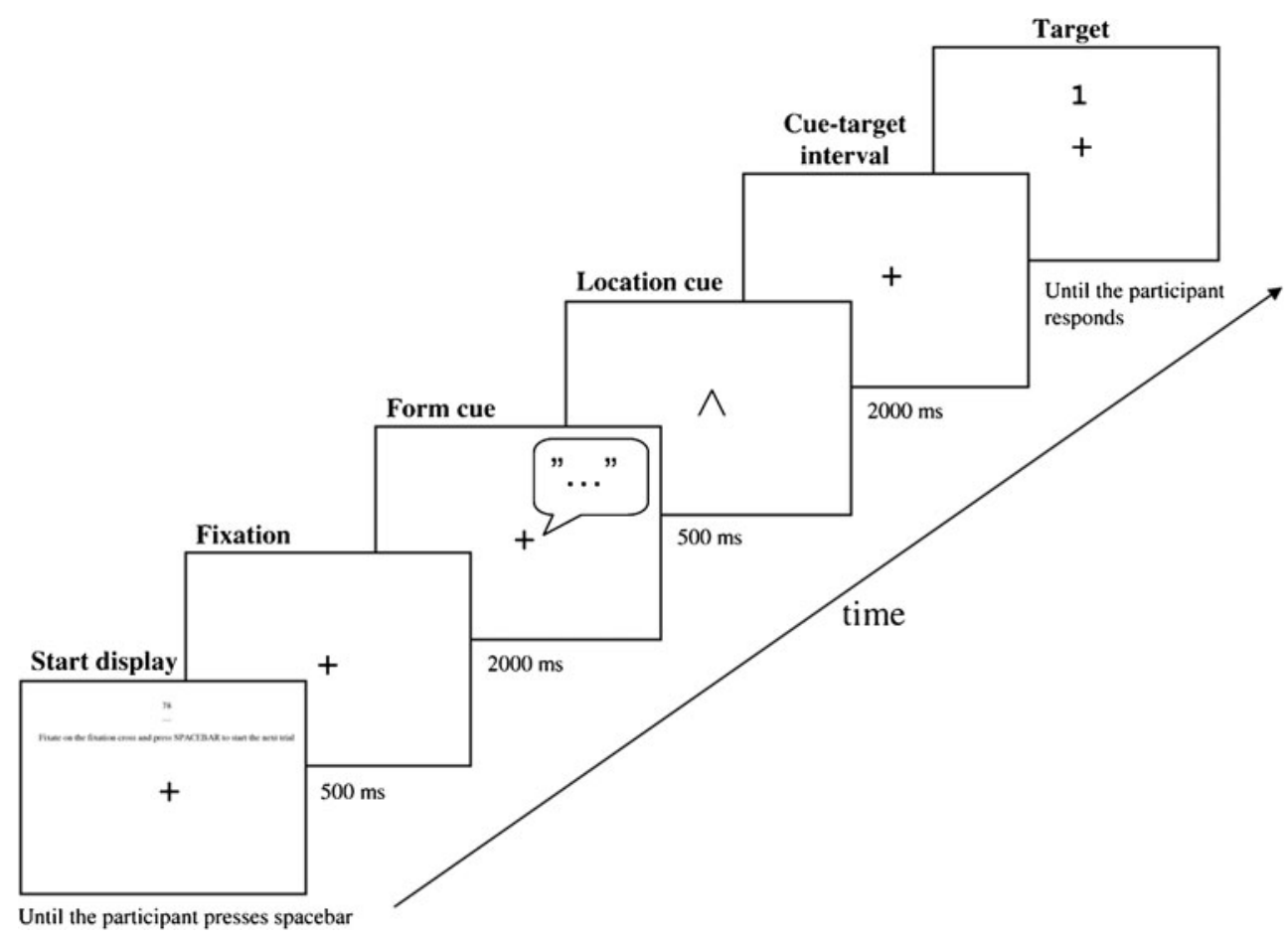

Instructions and experimental session

Each participant served individually in a single session comprising 512 experimental trials (duration approximately $75 \mathrm{~min}$ ). During the experiment, the participants were seated in a dimly lit room with their heads resting on a chinrest $700 \mathrm{~mm}$ from the monitor. Before the beginning of each experiment, the participants were shown printed illustrations of (a) the eight possible targets in their standard upright and all possible rotated orientations, (b) the nine location cues, and (c) the nine auditory form cues (nine small drawings of a loudspeaker beside the utterances in quotation marks). These illustrations were used as visual support, while the significance of the cues and the participants' task were explained verbally by the experimenter. Participants were told to pay attention to the information in both cues and to use it to prepare for the upcoming target. Moreover, they were asked to make their responses to the target as quickly as possible, while making as few errors as possible. Half of the participants responded to standard upright targets by pressing the tab key (left-hand response) and to rotated targets by pressing the enter key (right-hand response), and the reverse was the case for the other half of the participants. Finally, participants were instructed to fixate the fixation cross throughout each trial. A trial was counted as a trial with failure to fixate if the participant's gaze was not inside a small virtual square ( with its center at the fixation cross during the entire interval between the presentation of the location cue and the participant's response. After the instructions, participants performed 24 practice trials in the presence of the experimenter. Then the experiment was started, and the experimenter left the room.
Fig. 2 Target sets for Experiments 1-3

\section{a. Experiment 1}

\begin{tabular}{|c|c|}
\hline $\begin{array}{l}\text { Standard } \\
\text { orientation }\end{array}$ & $\begin{array}{l}\text { Rotated } \\
\text { orientations }\end{array}$ \\
\hline 1 & 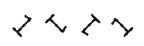 \\
\hline 2 & $\vec{c} \vec{c}$ \\
\hline 3 & $\checkmark \varepsilon<3$ \\
\hline 4 & $\nabla \otimes \Delta \Delta$ \\
\hline 5 & $\checkmark \leftrightarrow s ら$ \\
\hline 6 & 6996 \\
\hline 7 & $>v<\uparrow$ \\
\hline 8 & 8808 \\
\hline
\end{tabular}

\section{b. Experiment 2}

\begin{tabular}{|c|c|}
\hline $\begin{array}{l}\text { Standard } \\
\text { orientation }\end{array}$ & $\begin{array}{l}\text { Rotated } \\
\text { orientations }\end{array}$ \\
\hline$A$ & $\triangleleft \diamond \diamond \vee$ \\
\hline B & $\Delta \phi \beta b$ \\
\hline$C$ & \\
\hline $\mathrm{D}$ & \\
\hline$E$ & \\
\hline$F$ & $\hat{\wedge} \lambda \vee<$ \\
\hline $\mathrm{G}$ & ৫৩১৫ \\
\hline $\mathrm{H}$ & \\
\hline
\end{tabular}

\section{c. Experiment 3}

\section{Standard Rotated orientation orientations}

\begin{tabular}{|c|}
\hline$\triangleright \forall \varangle$ \\
\hline טכח \\
\hline mヨш \\
\hline ৩ ๑ \\
\hline$\pi X y$ \\
\hline ס \\
\hline$\dashv \perp \vdash$ \\
\hline$\langle\lambda\rangle$ \\
\hline
\end{tabular}




\section{Experiment 1}

Method

Participants A group of 33 students (23 women/10 men; mean age $=24.8$ years, ranging from 20 to 33 years) participated in the experiment for course credits or as paid volunteers. $^{3}$ Twenty-seven of the participants were right-handed.

Stimuli and design The digits 1, 2, 3, 4, 5, 6, 7, and 8 in Courier New bold font constituted the target set (see Fig. 2a). In the rotated condition, the digits were rotated 45, 135, 225, or $315 \mathrm{deg}$ from the standard upright orientation, with equally many occurrences of the four rotated orientations.

\section{Results}

Fixation control Participants who failed to fixate on more than $20 \%$ of the trials were excluded from the analysis. Ten of the participants were excluded on this basis (with failures to fixate on $33 \%, 35 \%, 36 \%, 36 \%, 43 \%, 50 \%, 66 \%, 67 \%$, $80 \%$, and $83 \%$ of the trials, respectively). For the remaining 23 participants, trials with failures to fixate were excluded from the analysis. This resulted in a loss of $6.2 \%$ of the trials.

Error rates The mean error rate was $3.5 \%(S D=2.8 \%)$. To test for systematic differences in error rates between the experimental conditions, the data were entered into a $2 \times 2 \times 2$ repeated measures ANOVA with Location Preknowledge (present vs. absent), Form Preknowledge (present vs. absent), and Orientation (standard upright vs. rotated) as factors. There was a significant main effect of orientation $(F=4.40$, $p=.048)$ reflecting slightly higher error rates for standard upright than for rotated digits $(4.2 \%, S D=3.7 \%$ vs. $2.8 \%$, $S D=2.6 \%$ ) and a significant main effect of location preknowledge $(F=6.5, p=.018)$ reflecting slightly higher error rates when location preknowledge was absent rather than present $(3.9 \%, S D=3.1 \%$ vs. $3.1 \%, S D=2.6 \%)$. No other main effects or interactions reached the .05 level of significance.

Response times Mean correct RTs were calculated for the four preknowledge conditions for standard upright and rotated digits separately, and the data were entered into a $2 \times$ $2 \times 2$ ANOVA as described for error rates. The mean values are plotted in the first column of Fig. 3, and the results of the ANOVA are summarized in Table 1. The ANOVA showed

\footnotetext{
$\overline{3}$ Originally, 15 participants were included in Experiment 1 . Upon request from an anonymous reviewer, we increased the number of participants.
}

-- - Location preknowledge absent

- Location preknowledge present

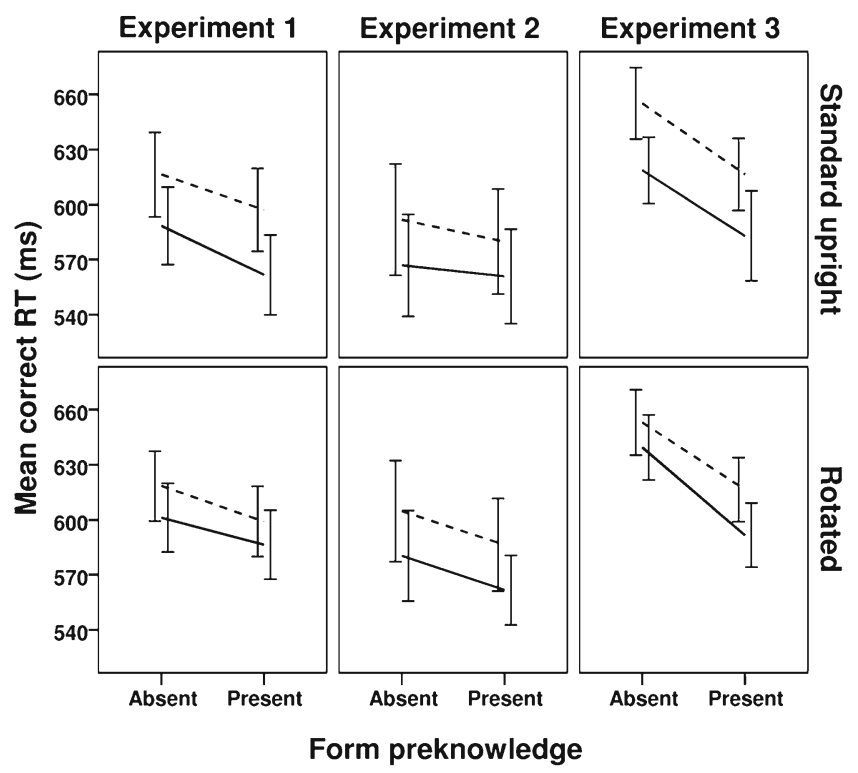

Fig. 3 Mean correct RTs, in milliseconds, for Experiments 1-3. Error bars represent \pm 1 standard error of the means. As indicated by the error bars, the between-subjects variation in mean scores was substantial for any given condition. However, the effects of the different cuing conditions were highly systematic, and according to repeated measures ANOVAs, the effects of location preknowledge and form preknowledge were highly significant (see Table 1)

highly significant main effects of both form preknowledge and location preknowledge, with faster RTs when preknowledge was present, but no significant interaction between the two types of preknowledge (for form preknowledge, $586 \mathrm{~ms}, S D=96 \mathrm{~ms}$, vs. $606 \mathrm{~ms}, S D=96 \mathrm{~ms}$; for location preknowledge, $584 \mathrm{~ms}, S D=94 \mathrm{~ms}$, vs. $608 \mathrm{~ms}, S D=$ $98 \mathrm{~ms}$ ). The main effect of orientation was not significant, but one interaction involving orientation reached significance: the two-way interaction between location preknowledge and orientation $(F=8.85, p=.007)$.

Finally, mean correct RTs were calculated for the standard upright and each of the four rotated orientations, and these mean values were entered into a repeated measures ANOVA with five levels of orientation angle (0, 45, 135 , 225 , and $315 \mathrm{deg})$. There was no significant effect of the orientation angle on RTs, $F(2.38,52.41)=2.50, p=.082$.

\section{Discussion}

Our finding of a main effect of location preknowledge replicated the well-established finding that spatial cuing of an upcoming target reduces the time it takes to carry out a discrimination task in relation to that target (e.g., Eriksen \& Yeh, 1985; Posner, 1980). Our finding of a main effect of form preknowledge is more controversial, but is consistent 
Table 1 ANOVAs on RTs in Experiments 1-3

The $p$ values are uncorrected for multiple comparisons. For $p$ values less than $1 / 7$, Bonferronicorrected $p$ values can be obtained by multiplying the stated $p$ values by a factor of 7 . ${ }^{*} p<.05 .{ }^{* *} p<.005$

\begin{tabular}{|c|c|c|c|c|c|c|}
\hline \multirow[t]{2}{*}{ Test of Within-Subjects Effects } & \multicolumn{2}{|c|}{ Experiment 1} & \multicolumn{2}{|c|}{ Experiment 2} & \multicolumn{2}{|c|}{ Experiment 3} \\
\hline & $F(1,22)$ & $p$ & $F(1,8)$ & $p$ & $F(1,12)$ & $p$ \\
\hline Location preknowledge (L) & 27.96 & $.000^{* *}$ & 17.28 & $.003^{* *}$ & 15.70 & $.002^{* *}$ \\
\hline Form preknowledge $(\mathrm{F})$ & 46.00 & $.000^{* *}$ & 6.18 & $.038^{*}$ & 51.17 & $.000^{* *}$ \\
\hline Orientation $(\mathrm{O})$ & 1.76 & .199 & 1.11 & .322 & 0.88 & .382 \\
\hline $\mathrm{L} \times \mathrm{F}$ & 0.09 & .762 & 0.53 & .490 & 0.31 & .585 \\
\hline $\mathrm{L} \times \mathrm{O}$ & 8.85 & $.007^{*}$ & 0.19 & .676 & 2.28 & .157 \\
\hline $\mathrm{F} \times \mathrm{O}$ & 1.91 & .181 & 1.25 & .296 & 0.82 & .382 \\
\hline $\mathrm{L} \times \mathrm{F} \times \mathrm{O}$ & 2.65 & .118 & 0.38 & .557 & 0.86 & .373 \\
\hline
\end{tabular}

with the results of at least one previous study (Kingstone, 1992). Other previous studies have failed to find effects of form preknowledge on RTs (Lambert \& Hockey, 1986; Theeuwes, 1989; but see, e.g., Wolfe, Butcher, Lee, \& Hyle, 2003, for clear evidence that preknowledge of a formrelated feature, such as the orientation of a bar-shaped orientation singleton target, facilitates visual search for the singleton). The only other RT effect that reached significance in Experiment 1 was the Location Preknowledge $\times$ Orientation interaction. Without venturing a detailed explanation, we speculated that, by means of a speed-accuracy trade-off, this interaction might be related to the only significant effects found in the error rates: the effects of location preknowledge and orientation.

\section{Experiment 2}

To test the generality of the results of Experiment 1, we repeated the experiment with new participants and a new target set.

\section{Method}

Participants A group of 14 healthy adults ( 8 women/6 men; mean age $=23.0$ years, ranging from 18 to 28 years) participated in the experiment as paid volunteers. All of the participants except one were right-handed.

Stimuli and design The capital letters A, B, C, D, E, F, G, and $\mathrm{H}$ in Consolas font constituted the target set (see Fig. 2b). In the rotated condition, the digits were rotated $45,135,225$, or $315 \mathrm{deg}$ from the standard upright orientation, with equally many occurrences of the four rotated orientations.

\section{Results}

Fixation control The participants who failed to fixate on more than $20 \%$ of the trials were excluded from the analysis. Four of the participants were excluded on this basis (with failures to fixate on $41 \%, 78 \%, 52 \%$, and $92 \%$ of the trials, respectively). One participant was excluded because no fixation data were collected due to technical problems with the eyetracker. For the remaining nine participants, trials with failures to fixate were excluded from the analysis. This resulted in the loss of $7.1 \%$ of the trials.

Error rates The mean error rate was $2.6 \%(S D=1.2 \%)$. To test for systematic differences in error rates between the experimental conditions, the data were entered into a $2 \times$ $2 \times 2$ repeated measures ANOVA with Location Preknowledge (present vs. absent), Form Preknowledge (present vs. absent), and Orientation (standard upright vs. rotated) as factors. No main effects or interactions approached significance.

Response times Mean correct RTs were calculated for the four preknowledge conditions for standard upright and rotated letters separately, and the data were entered into a $2 \times$ $2 \times 2$ ANOVA as described for the error rates. The mean values are plotted in the second column of Fig. 3, and the results of the ANOVA are summarized in Table 1. The ANOVA showed significant main effects of both location preknowledge and form preknowledge, with faster RTs when preknowledge was present (for form preknowledge, $572 \mathrm{~ms}, S D=73 \mathrm{~ms}$, vs. $586 \mathrm{~ms}, S D=81 \mathrm{~ms}$; for location preknowledge, $567 \mathrm{~ms}, S D=71 \mathrm{~ms}$, vs. $591 \mathrm{~ms}, S D=82 \mathrm{~ms}$ ). No other main effects or interactions were significant.

Finally, mean correct RTs were calculated for the standard upright and each of the four rotated orientations, and these mean values were entered into a repeated measures ANOVA with five levels of orientation angle $(0,45,135$, 225 , and $315 \mathrm{deg})$. There was no significant effect of the orientation angle on RTs, $F(4,32)=2.11, p=.102$.

Discussion of Experiments 1 and 2

The ANOVA of the data from Experiment 1 showed three significant effects: the main effects of location preknowledge 
and form preknowledge, as well as the Location Preknowledge $\times$ Orientation interaction. Analyzed in the same way, the data from Experiment 2 showed two significant effects: the main effect of location preknowledge and the main effect of form preknowledge. In Experiment 2, there was no Location Preknowledge $\times$ Orientation interaction. Moreover, the pattern of differences in error rates between conditions observed in Experiment 1 was not present in Experiment 2. This is consistent with the notion that the Location Preknowledge $\times$ Orientation interaction observed in the Experiment 1 RTs was related to the significant effects of location preknowledge and orientation on the error rates observed in the same experiment. Taken together, the results of Experiments 1 and 2 suggest that (a) performance in these experiments benefited from both preknowledge of form and preknowledge of location, and (b) the effects of the two types of preknowledge on mean RTs were approximately additive.

\section{Experiment 3}

As a further test of the generality of our results, we attempted a replication of Experiments 1 and 2 with new participants, a new target set, and a new type of instruction: We explicitly instructed participants to generate mental images of the upcoming form, when preknowledge of form was available.

\section{Method}

Participants A group of 15 healthy adults (8 women/7 men; mean age $=25.5$ years, ranging from 20 to 39 years) participated in the experiment as paid volunteers. All were righthanded.

Stimuli and design The capital letters A, C, E, G, K, R, T, and $\mathrm{Y}$ in Consolas font constituted the target set, and instead of four rotated orientations, as in Experiments 1 and 2, only three rotated orientations were used in Experiment 3namely, 90, 180, and $270 \mathrm{deg}$ from the standard upright orientation (see Fig. 2c)—with equally many occurrences of the three rotated orientations.

Instructions In addition to the instructions described in the General Method section, participants also read a sheet of written instructions in which they were explicitly asked to prepare for the particular upcoming letter (when known) by generating a realistic mental image of its form. When both form preknowledge and location preknowledge were present, the participants were instructed to generate a mental image of the letter at the exact position where it would occur. When only the location was known, they should simply focus their spatial attention on the relevant position, and when no preknowledge was present, they should stay "attentive and open." In order to assure that the participants understood these written instructions properly, the experimenter questioned them on how they should use the form and location cues before the experiment started, and the instructions were repeated verbally if any misunderstandings were apparent. After the experiment, participants were given a debriefing questionnaire in which they were asked to estimate on what percentages of the trials they had been able to generate a realistic mental image of the upcoming letter (when known) before it occurred, both when they had and when they did not have preknowledge of its location.

\section{Results}

Fixation control The participants who failed to fixate on more than $20 \%$ of the trials were excluded from the analysis. Two participants were excluded on this basis (with failures to fixate on $31 \%$ and $79 \%$ of the trials, respectively). For the remaining 13 participants, trials with failures to fixate were excluded from the analysis. This resulted in a loss of $3.4 \%$ of the trials.

Error rates The mean error rate was $3.2 \%(S D=2.0 \%)$. To test for systematic differences in error rates between the experimental conditions, the data were entered into a $2 \times$ $2 \times 2$ repeated measures ANOVA with Location Preknowledge (present vs. absent), Form Preknowledge (present vs. absent), and Orientation (standard upright vs. rotated) as factors. No main effects or interactions approached significance.

Response times Mean correct RTs were calculated for the four preknowledge conditions for standard upright and rotated letters separately, and the data were entered into a $2 \times 2 \times 2$ ANOVA as described for the error rates. The mean values are plotted in the third column of Fig. 3, and the results of the ANOVA are shown in Table 1. The ANOVA showed significant main effects of both location preknowledge and form preknowledge, with faster RTs when preknowledge was present (for form preknowledge, $602 \mathrm{~ms}, S D=67 \mathrm{~ms}$, vs. $642 \mathrm{~ms}, S D=$ $62 \mathrm{~ms}$; for location preknowledge, $608 \mathrm{~ms}, S D=66 \mathrm{~ms}$, vs. $635 \mathrm{~ms}, S D=65 \mathrm{~ms})$. No other main effects or interactions were significant.

Finally, mean correct RTs were calculated for the standard upright and each of the three rotated orientations, and these mean values were entered into a repeated measures ANOVA with four levels of orientation angle (0, 90, 180, and $270 \mathrm{deg})$. There was no significant effect of the orientation angle on RTs, $F(3,36)=1.42, p=.253$. 
Subjective reports of mental imagery Averaging estimated percentages across participants, the participants reported that they had been able to generate a realistic mental image of the upcoming letter (when known) before it occurred on $75 \%$ of the trials $(S D=21 \%)$ when they had simultaneous preknowledge of the letter's location, and on $66 \%$ of the trials $(S D=24 \%)$ when they did not have preknowledge of the letter's location.

\section{Discussion}

The results of Experiment 3 corroborated the assumptions that (a) performance in these experiments benefited from both preknowledge of form and preknowledge of location and (b) the effects of the two types of preknowledge on mean RTs were approximately additive. These results were obtained although participants were instructed to prepare for a known upcoming letter by generating a mental image of the letter and to prepare for a known letter upcoming at a particular known location by generating a mental image of the letter at the given location.

\section{Analysis of the nonfixation data}

Because of the large number of excluded participants due to fixation failures in Experiment $1(N=10)$, we decided to look at their data to see whether fixation changed the pattern of the results. An ANOVA on the error rates on the trials with failures to fixate from these 10 participants (hereafter designated the nonfixation data) showed no significant main effects or interactions. An ANOVA on the RTs on the same trials yielded essentially the same results as those already reported for Experiments 1-3. The nonfixation data showed significant main effects of both form preknowledge $[F(1,9)=5.57, p=.043]$ and location preknowledge $[F(1,9)=14.37, p=.004]$, with faster RTs when preknowledge was present than when it was absent, but no interaction between the two types of preknowledge $[F(1,9)=0.39, p=.548]$. No other main effects or interactions were significant. Moreover, the RT effects of form preknowledge and location preknowledge found in the nonfixation data were of similar magnitude to those in the original data from Experiment 1 shown in Fig. 3 (for form preknowledge, $23 \mathrm{~ms}$ in the nonfixation data vs. $20 \mathrm{~ms}$ in the original data; for location preknowledge, $26 \mathrm{~ms}$ in the nonfixation data vs. $24 \mathrm{~ms}$ in the original data). Thus, fixation did not seem to change the pattern of results in our experiments. This finding enhances the legitimacy of comparing our results with those of Kingstone (1992) and Lambert and Hockey (1986), who did not control for fixation errors.

\section{General discussion}

The overall picture that emerged from Experiments 1-3 was, first, that the time taken to make an orientation judgment of an alphanumeric character is substantially reduced when the location or the form of the upcoming character is known in advance, and, second, that the effects of form preknowledge and location preknowledge on mean RTs are approximately additive.

Main effects of location preknowledge and form preknowledge

Our finding of a robust effect of location preknowledge across the three experiments is not surprising, given the strong evidence that we can selectively prepare to process visual information at a specific location in the visual field (see, e.g., Downing, 1988; Posner, 1980). However, previous evidence of a similar effect of preknowledge of form on visual processing has been more sparse and less consistent.

Lambert and Hockey (1986, Exp. 1) found no effect of form cuing when the participants were instructed to make use of both the location cue and the form cue, although the researchers did find a clear effect of location preknowledge in this condition. They did, however, find a small effect of form precuing in a condition in which participants were instructed to use only the form cue and to ignore the location cue. Two special features of Lambert and Hockey's design may explain this divergence regarding the effect of form preknowledge on RTs between their results, on one side, and our results and those of Kingstone (1992), on the other. First, the form preknowledge provided in Lambert and Hockey's study was only valid in $66 \%$ of the cases, while we gave participants $100 \%$-valid preknowledge. Kingstone found a clear effect of form preknowledge with an $80 \%$ valid cue, but he also showed that there was a significantly lower effect of form cuing when the cue was $70 \%$ rather than $90 \%$ valid. It is possible that the $66 \%$ validity used in Lambert and Hockey's study was too low to yield an effect for form preknowledge when location preknowledge should also be used. Second, the interval between the cue and the target was only $600 \mathrm{~ms}$ in Lambert and Hockey's study, as compared to 1,500 ms in Kingstone's study and 2,000 ms in ours. Hence, the participants in Lambert and Hockey's study may have had too little time to prepare for both the location and the form, and may have prioritized the preparation for location (see Wolfe, Horowitz, Kenner, Hyle, \& Vasan, 2004, for data on the time taken to shift selection criterion in visual search).

Theeuwes (1989) also reported no effect of form preknowledge on RTs. In this study, a compound target composed of a geometrical form (circle or diamond) encircling a line segment was used. The target occurred to the left or to 
the right of a fixation cross in a display with dispersed, randomly oriented line segments. The participants' task was to judge the orientation of the line segment inside the geometrical form. However, the shape of the encircling geometrical form was what was cued (with $75 \%$ validity). Hence, the part of the target about which the participants received form preknowledge was not the same as the part that should be used to solve the required task, so the form preknowledge was not relevant to the response task. This may explain the discrepancy between Theeuwes's findings and ours.

The independence of form anticipation from location preknowledge

Relation to mental imagery Drawing on the literature on visual mental imagery, we presented the notion that visual form anticipation is achieved through depictive neural activations in topographically organized visual areas such as V1. In some conditions, this notion may be true, but we did not find support for such spatially bound form anticipation in our study. We proposed that if form preknowledge of an upcoming visual stimulus had an effect on the RT to the stimulus only when the location of the upcoming stimulus was known, but not when the location was unknown, this would support the view that visual form anticipation is intrinsically spatially bound, and possibly relies on perception-like activations in topographically organized visual areas on the neural level. In our study, however, we found efficient anticipation of a specific visual form in the absence of concurrent knowledge of the form's location, suggesting that form anticipation was done by activation of location-invariant representations rather than by depictive perception-like activations in topographically organized parts of the visual system. The support for such locationinvariant representation has great implications for our understanding of how the selective preparation for specific forms can be brought about by our visual system.

On the neural level, a visual association area, the inferior temporal cortex, has long been related to the representation of visual objects independent of their spatial location (e.g., Gross, Rocha-Miranda, \& Bender, 1972; Tanaka, 1996). This area contains cells with very large receptive fields that respond selectively to distinct visual forms, and it might thus be a candidate for a neural structure mediating the effects of anticipation of visual forms whose spatial location is unspecified. Future studies combining brain imaging with an experimental paradigm similar to ours could be useful in investigating this matter further.

Relation to visual priming While the relation between visual anticipation and mental imagery appears less close than has been proposed in the perceptual anticipation theory of visual imagery (Kosslyn \& Thompson, 2003), visual anticipation may be closely related to another well-known visual phenomenon: visual priming. Priming is thought to operate largely automatically (Kristjánsson, 2008; Maljkovic \& Nakayama, 1996), but the effects of priming and anticipation in terms of behavioral benefits in response to anticipated or primed items or features may share underlying neural mechanisms. In this light, it is interesting to note that priming of location and color have been found to have additive effects on RTs (Maljkovic \& Nakayama, 1996). Moreover, a neurophysiological distinction and a neuropsychological dissociation between location and color priming have been found, with location priming operating through frontal and contralateral parietal networks known to be involved in the deployment of attention in space, and color priming operating through inferior temporal areas involved in color processing (Kristjánsson, Vuilleumier, Malhotra, Husain, \& Driver, 2005; Kristjánsson, Vuilleumier, Schwartz, Macaluso, \& Driver, 2007). Future studies combining location priming with form priming could be useful in elucidating the relationship between anticipation and priming in visual perception.

\section{Serial-stage interpretation}

By the additive-factors logic developed by Sternberg (1969, 1998; see also Roberts \& Sternberg, 1993), the additive effects on mean RTs of two factors such as form preknowledge and location preknowledge suggest that the mechanisms underlying the effects of the individual factors operate in separate stages of a serial process rather than operating in the same stage. By this logic, our results suggest that the preknowledge of form and location affected two functionally independent, serial stages of processing.

It seems plausible that the first stage consisted in directing attention to the location of the upcoming stimulus. When the stimulus location was precued, attention was directed to the location on the stimulus screen at which the stimulus would appear, before the stimulus was presented. Otherwise, when location cuing was neutral, attention was not directed to the stimulus location until the stimulus appeared, which caused a delay with a mean of $x$ ms relative to the condition in which the location was precued. This delay was independent of any precuing of form.

It also seems plausible that the second stage of processing consisted in discriminating upright from rotated stimuli. When the form of the stimulus was precued, the orientation discrimination was relatively fast. Otherwise, when form cuing was neutral, the orientation discrimination was more difficult, which caused a delay with a mean of $y$ ms relative to the condition in which the form was precued. This delay was independent of any precuing of location. Hence, by our serial-stage interpretation of the results, precuing of location speeded up processing by $x \mathrm{~ms}$, regardless of whether form was precued, and precuing of form speeded up processing 
by $y \mathrm{~ms}$, regardless of whether location was precued. This explains why the effects of the two types of cuing were additive.

\section{References}

Anokhin, P. K. (1974). Biology and neurophysiology of the conditioned reflex and its role in adaptive behavior (S. A. Corson, Scientific \& Trans. Ed.). Oxford, U.K.: Pergamon Press.

Barsalou, L. W. (2009). Simulation, situated conceptualization, and prediction. Philosophical Transactions of the Royal Society B, $364,1281-1289$.

Bastiaansen, M. C. M., \& Brunia, C. H. M. (2001). Anticipatory attention: An event-related desynchronization approach. International Journal of Psychophysiology, 43, 91-107.

Berlyne, D. E. (1963). Motivational problems raised by exploratory and epistemic behavior. In S. Koch (Ed.), Psychology: A study of a science: Vol. 5. The process areas, the person, and some applied fields: Their place in psychology and in science (pp. 284-364). New York, NY: McGraw-Hill.

Carlsson, K., Petrovic, P., Skare, S., Petersson, K. M., \& Ingvar, M. (2000). Tickling expectations: Neural processing in anticipation of a sensory stimulus. Journal of Cognitive Neuroscience, 12, 691-703.

Downing, C. J. (1988). Expectancy and visual-spatial attention: Effects on perceptual quality. Journal of Experimental Psychology: Human Perception and Performance, 14, 188-202. doi:10.1037/0096-1523.14.2.188

Dykes, J. R., \& Pascal, V. (1981). The effect of stimulus probability on the perceptual processing of letters. Journal of Experimental Psychology: Human Perception and Performance, 7, 528-537.

Eriksen, C. W., \& Yeh, Y. (1985). Allocation of attention in the visual field. Journal of Experimental Psychology: Human Perception and Performance, 11, 583-597. doi:10.1037/0096-1523.11.5.583

Farah, M. J. (1985). Psychophysical evidence for a shared representational medium for mental images and percepts. Journal of Experimental Psychology: General, 114, 91-103.

Farah, M. J. (1989). Mechanisms of imagery-perception interaction. Journal of Experimental Psychology: Human Perception and Performance, 15, 203-211.

Farah, M. J., \& Smith, A. F. (1983). Perceptual interference and facilitation with auditory imagery. Perception \& Psychophysics, 33, 475-478.

Farah, M. J., Soso, M. J., \& Dasheiff, R. M. (1992). Visual angle of the mind's eye before and after unilateral occipital lobectomy. Journal of Experimental Psychology. Human Perception and Performance, 18, 241-246.

Feigenberg, I. M. (1969). Probabilistic prognosis and its significance in normal and pathological subjects. In M. Cole \& I. Maltzman (Eds.), A handbook of contemporary Soviet psychology (pp. 354-369). New York, NY: Basic Books.

Gross, C. G., Rocha-Miranda, C. E., \& Bender, D. B. (1972). Visual properties of neurons in inferotemporal cortex of the Macaque. Journal of Neurophysiology, 35, 96-111.

Hume, D. (1896). In L. A. Selby-Bigge (Ed.), A treatise of human nature. Oxford, U.K: Clarendon Press. Original work published 1739.

Jonides, J., \& Mack, R. (1984). On the cost and benefit of cost and benefit. Psychological Bulletin, 96, 29-44. doi:10.1037/00332909.96.1.29

Kingstone, A. (1992). Combining expectancies. Quarterly Journal of Experimental Psychology, 44A, 69-104. doi:10.1080/ 14640749208401284
Kingstone, A., \& Klein, R. (1991). Combining shape and position expectancies: Hierarchical processing and selective inhibition. Journal of Experimental Psychology: Human Perception and Performance, 17, 512-519.

Kosslyn, S. M., Pascual-Leone, A., Felician, O., Camposano, S., Keenan, J. P., Thompson, W. L., \& Alpert, N. M. (1999). The role of area 17 in visual imagery: Convergent evidence from PET and rTMS. Science, 284, 167-170. doi:10.1126/ science.284.5411.167

Kosslyn, S. M., \& Thompson, W. L. (2003). When is early visual cortex activated during visual mental imagery? Psychological Bulletin, 129, 723-746.

Kristjánsson, Á. (2008). "I know what you did on the last trial"-A selective review of research on priming in visual search. Frontiers in Bioscience, 13, 1171-1181.

Kristjánsson, Á., Vuilleumier, P., Malhotra, P., Husain, M., \& Driver, J. (2005). Priming of color and position during visual search in unilateral spatial neglect. Journal of Cognitive Neuroscience, 17, $859-873$

Kristjánsson, Á., Vuilleumier, P., Schwartz, S., Macaluso, E., \& Driver, J. (2007). Neural basis for priming of pop-out revealed with fMRI. Cerebral Cortex, 17, 1612-1624.

Lambert, A. J., \& Hockey, R. (1986). Selective attention and performance with a multidimensional visual display. Journal of Experimental Psychology: Human Perception and Performance, 12, 484-495.

Llinás, R. R. (2001). I of the vortex: From neurons to self. Cambridge, MA: MIT Press.

Maljkovic, V., \& Nakayama, K. (1996). Priming of pop-out: II. The role of position. Perception \& Psychophysics, 58, 977-991. doi:10.3758/BF03206826

Mattes, S., Ulrich, R., \& Miller, J. (2002). Response force in RT tasks: Isolating effects of stimulus probability and response probability. Visual Cognition, 9, 477-501.

Miller, J., \& Anbar, R. (1981). Expectancy and frequency effects on perceptual and motor systems in choice reaction time. Memory \& Cognition, 9, 631-641.

Neisser, U. (1976). Cognition and reality: Principles and implications of cognitive psychology. New York, NY: Freeman.

Neisser, U. (1978). Anticipations, images, and introspection. Cognition, 6, 169-174.

Niemi, P., \& Näätänen, R. (1981). Foreperiod and simple reaction time. Psychological Bulletin, 89, 133-162. doi:10.1037/00332909.89.1.133

Nobre, A., Correa, A., \& Coull, J. (2007). The hazards of time. Current Opinion in Neurobiology, 17, 465-470.

Peterson, M. J., \& Graham, S. E. (1974). Visual detection and visual imagery. Journal of Experimental Psychology, 103, 509-514.

Pezzulo, G., Hoffmann, J., \& Falcone, R. (2007). Anticipation and anticipatory behavior. Cognitive Processing, 8, 67-70.

Posner, M. I. (1980). Orienting of attention. Quarterly Journal of Experimental Psychology, 32, 3-25. doi:10.1080/ 00335558008248231

Roberts, S., \& Sternberg, S. (1993). The meaning of additive reactiontime effects: Tests of three alternatives. In D. E. Meyer \& S. Kornblum (Eds.), Attention and performance XIV: Synergies in experimental psychology, artificial intelligence, and cognitive neuroscience (pp. 611-653). Cambridge, MA: MIT Press.

Sokolov, E. N., Spinks, J. A., Näätänen, R., \& Lyytinen, H. (Eds.). (2002). The orienting response in information processing. Mahwah, NJ: Erlbaum.

Sternberg, S. (1969). The discovery of processing stages: Extension of Donders' method. Acta Psychologica, 30, 276-315. doi:10.1016/ 0001-6918(69)90055-9

Sternberg, S. (1998). Discovering mental processing stages: The method of additive factors. In D. N. Osherson (Series Ed.) \& D. 
Scarborough \& S. Sternberg (Vol. Eds.), An invitation to cognitive science: Vol. 4. Methods, models, and conceptual issues (2nd ed., pp. 703-863). Cambridge, MA: MIT Press.

Summerfield, C., \& Egner, T. (2009). Expectation (and attention) in visual cognition. Trends in Cognitive Sciences, 13, 403-409.

Sylvester, C. M., Shulman, G. L., Jack, A. I., \& Corbetta, M. (2007). Asymmetry of anticipatory activity in visual cortex predicts the locus of attention and perception. Journal of Neuroscience, 27, 14424-14433.

Tanaka, K. (1996). Inferotemporal cortex and object vision. Annual Review of Neuroscience, 19, 109-139.

Theeuwes, J. (1989). Effects of location and form cuing on the allocation of attention in the visual field. Acta Psychologica, 72, 177-192.

Vangkilde, S., Coull, J. T., \& Bundesen, C. (2012). Great expectations: Temporal expectation modulates perceptual processing speed. Journal of Experimental Psychology: Human Perception and Performance. doi:10.1037/a0026343

Voisin, J., Bidet-Caulet, A., Bertrand, O., \& Fonlupt, P. (2006). Listening in silence activates auditory areas: A functional magnetic resonance imaging study. Journal of Neuroscience, 26, 273-278.
Wolfe, J. M., Butcher, S. J., Lee, C., \& Hyle, M. (2003). Changing your mind: On the contributions of top-down and bottom-up guidance in visual search for feature singletons. Journal of Experimental Psychology: Human Perception and Performance, 29, 483-502. doi:10.1037/0096-1523.29.2.483

Wolfe, J. M., Horowitz, T. S., Kenner, N., Hyle, M., \& Vasan, N. (2004). How fast can you change your mind? The speed of topdown guidance in visual search. Vision Research, 44, 1411-1426. doi:10.1016/j.visres.2003.11.024

\section{Author note}

Thanks are due Denis Yukhnenko, Clara Turnstedt, and Annemarie Hilkjær for assistance in setting up the experiments and collecting the data; Rasmus Lunau and Anders Petersen for technical assistance with the eyetracking equipment; and Maria Nordfang for comments on an earlier draft of this article. 